\title{
Pergeseran Nilai-nilai Moral Masyarakat dan Implikasinya terhadap Moralitas Remaja di Kecamatan IV Nagari Bayang Utara Kabupaten Pesisir Selatan (Kasus Hamil Diluar Nikah)
}

\author{
Cici Yolanda, Fatmariza \\ Program Studi Pendidikan Pancasila dan Kewarganegaraan \\ Universitas Negeri Padang \\ E-mail: ciyolanda1996@gmail.com
}

\begin{abstract}
ABSTRAK
Artikel ini bertujuan untuk menggambarkan pergeseran nilai-nilai moral masyarakat, faktor penyebab terjadinya pergeseran nilai-nilai moral masyarakat dan upaya dalam menanggulangi pergeseran nilai-nilai moral masyarakat di Kecamatan IV Nagari Bayang Utara. Penelitian ini menggunakan penelitian deskriptif kualitatif. Hasil penelitian ini menggambarkan pergeseran nilai-nilai moral masyarakat yaitu sikap anak muda yang suka berbohong, tidak menghormati yang lebih tua, guru dan Datuak/niniak mamak. Kurangnya partisipasi dalam mengikuti kegiatan keagamaan, malas untuk mengerjakan sholat baik di mesjid maupun di rumah. Rasa menghormati dan menghargai di lingkungan masyarakat yang sudah jarang terlihat. Faktor yang menyebabkan terjadinya pergeseran nila-nilai moral masyarakat yaitu kurang tertanamnya nilai agama masyarakat, kurangnya kontrol sosial masyarakat dan kurangnya kontrol orang tua. Sejauh ini Upaya yang dilakukan untuk menanggulangi pergeseran nilai moral masyarakat yaitu melalui upaya preventif dari pemerintah, tokoh agama dan tokoh adat dengan diadakannya pelatihan khutbah jum'at dan dibentuknya arena trabas, sementara itu tokoh adat memberikan nasehat dan pengarahan mengenai pergeseran nila-nilai moral yang telah mengakibatkan terjadinya hamil diluar nikah dan upaya refresif dari orang tua dan masyarakat yaitu menasehati anak dan meningkatkan kontrol terhadap anak. Jadi, dapat disimpulkan bahwa telah terjadi pergeseran nilai-nilai moral masyarakat di Kecamatan IV Nagari Bayang Utara dari zaman dahulu ke zaman sekarang yang mana pergeseran nila-nilai ini moral menimbulkan permasalahanpermasalahan di lingkungan masyarakat salah satunya yaitu hamil diluar nikah.
\end{abstract}

Kata Kunci: Pergeseran, nilai moral, hamil diluar nikah

\section{ABSTRACT}

This article aims to describe the shift in the moral values of society, the causal factor of the shift in people's moral values and efforts in tackling the moral values of people in the Kecamatan IV Nagari Bayang Utara. This research uses qualitative descriptive research. The results of this research describe the shift of people's moral values, which are attitudes of young children who like to lie, not respect the older, teachers and datuak/niniak mamak. Lack of participation in participating in religious activities, lazy to do prayers both in the mosque and at home. Respect and appreciation in a community environment that is rarely seen. Factors that cause the occurrence of shifting indigo-the moral value of society is the lack of the value of the religious values of society, the lack of social control of society and the lack of parental control. So far, the effort to tackle the moral value of the people is through the preventive efforts of the Government, religious figures and indigenous people with the training of the 
Friday circumcision and the establishment of the arena Trabas, while the customary figure Provide advice and guidance on the shift in the moral values that have resulted in the occurrence of pregnant by marriage and the refresif efforts of parents and society are advised children and improve the control of children. So, it can be concluded that there has been a shift in the moral values of society in the Kecamatan IV Nagari Bayang Utara of the Shadows from time to time today where the shifting tilapia-this moral value raises problems in the environment The community is pregnant outside of marriage.

Keywords : Shifting, Moral values, Unwed Pregnancy

\section{PENDAHULUAN}

Masyarakat dan moral tidak dapat dipisahkan dalam kehidupan manusia. Moral merupakan pedoman atau tolak ukur atas baik buruknya manusia dalam berperilaku. Masyarakat merupakan sekolompok manusia yang hidup saling berinteraksi dengan tujuan agar terpenuhinya kebutuhan dasar hidupnya dan memiliki kepentingan serta tujuan bersama. Namun ketika moral dalam kehidupan masyarakat sudah mengalami pergeseran maka akan menyebabkan terjadinya permasalahan-permasalahan perilaku masyarakat dalam lingkungan kehidupan.

Permasalahan-permasalahan

yang terjadi dalam kehidupan masyarakat dimana pada zaman dahulu anak-anak muda sangat sopan berbicara kepada orang tua dan mereka selalu jujur dalam berkatakata, anak-anak muda yang rajin untuk mengikuti kegiatan keagamaan dan rajin sholat berjama'ah di mesjid dan anak-anak muda yang selalu sopan ketika berbicara dengan orang yang lebih tua seperti kepada guru, dahulu ketika anak-anak muda bertemu dengan guru di jalan kalau bertemu guru mereka langsung bersalaman. Namun, karena adanya pergeseran nilai-nilai moral masyarakat membawa perubahan bagi anak-anak muda atau masyarakat zaman sekarang dimana anak-anak muda yang suka berbohong, berbicara tidak sopan dan melawan orang tua, malas mengikuti kegiatan keagamaan dan malas beribadah di mesjid maupun di rumah serta tidak adanya sopan santun kepada orang yang lebih tua seperti kepada Guru, niniak mamak dan anggota masyarakat lainnya. Pergeseran nila-nilai moral yang terjadi dalam kehidupan masyarakat tentunya disebabkan oleh beberapa faktor yaitu kurang tertanamnya nilai religius/agama, kurangnya kontrol sosial masyarakat dan kurangnya kontrol orang tua. Kontrol orang tua merupakan hal yang sangat berpengaruh besar terhadap perilaku anak-anak muda sekarang.

Menurut Willis (2010: 82) “orang tua menciptakan komunikasi yang lancar antar sesama anggota keluarga misalnya dengan makan bersama, sholat berjama'ah dan memberikan pengarahan." tapi pada kenyataannya orang tua lebih mementingkan untuk memenuhi kebutuhannya.

Untuk mengatasi pergeseran nilai-nilai moral masyarakat ini diperlukan upaya dari pemerintah, tokoh agama, tokoh adat, tokoh masyarakat dan orang tua. Adapun upaya yang dilakukan dalam menanggulangi pergeseran nilai moral masyarakat yaitu diadakannya pelatihan khutbah Jum'at, 
dibentuknya arena trabas, memberikan nasehat dan arahan kepada anak-anak muda serta meningkatkan kontrol terhapan anak agar pergeseran nilai moral masyarakat tidak terus terjadi. Apabila pergeseran nilai moral masyarakat terus dibiarkan maka akan semakin banyaknya kasus yang terjadi dalam lingkungan masyarakat. Seperti salah satu akibat dari pergeseran nilai moral masyarakat yang dialami oleh anakanak perempuan yanitu hamil diluar nikah. Hamil diluar nikah pada umumnya terjadi pada anak-anak yang jauh dari orang tua dimana orang tua lepas kontrol terhadap keseharian dan lingkungan mereka.

Menurut penelitian yang dilakukan Crockett, L.J et al,. (2003) dari University of Nebraska mengenai seksualitas remaja menyebutkan beragam faktor yang dapat mempengaruhi perilaku seksual remaja diantaranya pengaruh biologis, sosiokultural, keluarga, teman sebaya, lingkungan, media dan kebiasaan. Dalam penelitiannya diungkapkan pengaruh keluarga dalam hal ini kontrol orang tua menjadi salah satu faktor yang mempengaruhi perilaku sesksual remaja.

Penelitian terdahulu yang terkait dengan penelitian ini yaitu:

1. Penelitian oleh Dina Pebriani (2014) dengan judul penelitian yaitu : Faktor penyebab menurunnya moral remaja dan upaya orang tua dalam mengatasinya (Studi di Nagari Lansek Kadok Kecamatan Rao Selatan Kabupaten Pasaman). Fokus penelitian ini adalah apa saja yang menjadi penyebab menurunya moral remaja dan bagaimana upaya orang tua dalam mengatasinya.

2. Penelitian oleh Sulheri Garizing (2016) dengan judul Degradasi Moral Dikalangan Peserta Didik di SMA Negeri 1 Pinrang. Fokus penelitian ini yaitu moralitas peserta didik dan faktor penyebab terjadinya degradasi moral pada peserta didik.

Berdasarkan penelitian terdahulu diatas terdapat perbedaan pada fokus penelitian, dalam penelitian peneliti lebih menfokuskan pada pergeseran nilai-nilai moral masyarakat, faktor penyebab terjadinya pergeseran nilai-nilai moral masyarakat dan upaya dalam menanggulangi pergeseran nilai-nilai moral masyarakat yang mengakibatkan hamil diluar nikah.

Apabila permasalahan moral ini terus dibiarkan maka akan muncul permasalahan-permasalahan dan perilaku-perilaku amoral lainnya dalam kehidupan masyarakat.

\section{METODE PENELITIAN}

Metode penelitian yang digunakan adalah penelitian kualitatif. Peneliti menggunakan metode ini karena penelitian ini berusaha mengetahui pergeseran nilai-nilai moral masyarakat, faktor penyebab pergeseran nilai-nilai moral masyarakat dan upaya dalam menanggulangi pergeseran nilai-nilai moral masyarakat, dalam penelitian ini peneliti terjun langsung ke lapangan untuk observasi dan wawancara langsung kepada informan penelitian dan data yang dihasilkan yaitu bersifat deskriptif berupa kata-kata tertulis dan lisan dari informan penelitian yang dapat menggambarkan keadaan objek 
zaman dahulu dengan yang sekarang. Lokasi penelitian ini adalah di Kecamatan IV Nagari Bayang Utara. Peneliti mengambil lokasi penelitian di Kecamatan IV Nagari Bayang Utara karena adanya kasus hamil diluar nikah yang diasumsikan sebagai salah satu akibat dari pergeseran nilai-nilai moral masyarakat. Jenis data yang digunakan yaitu data primer dan data sekunder. Teknik pengumpulan data dalam penelitian ini adalah Observasi, wawancara dan studi dokumentasi. Teknik pengujian Keabsahan data yaitu menggunakan Triangulasi sumber dan Melakukan member check. Setelah melakukan pengujian keabsahan data peneliti melakukan analisis data melalui tahap seleksi data, tahap reduksi data, tahap penyajian data dan tahap penarikan kesimpulan.

\section{HASIL DAN PEMBAHASAN}

1. Bentuk-bentuk pergeseran nilai moral masyarakat di Kecamatan IV Nagari Bayang Utara

\section{Pergeseran Nilai-nilai Moral Masyarakat di Kecamatan IV Nagari Bayang Utara}

1) Pergeseran Nilai Moral Individual Menurut Sulistyorini dalam Calvien (2016: 20) Nilai moral individual adalah moral individual yang menyangkut aturan yang perlu dilakukan manusia dalam kehidupan pribadinya seperti Disiplin, jujur, menghormati dan menghargai, rendah hati dan hati-hati dalam melakukan sesuatu. Nilai moral individual di Kecamatan IV Nagari Bayang Utara yang ada pada zaman dahulu telah mengalami pergeseran pada zaman sekarang. Dahulu masyarakat sangatlah jujur dalam bersikap, menghormati dan menghargai orang yang lebih tua, berbicara sopan kepada orang tua dan orang lain serta disiplin dalam mengerjakan sesuatu. Namun, seiring berkembangnya zaman terjadilah Pergeseran nilai moral individual di Kecamatan IV Nagari Bayang Utara yaitu dengan banyaknya sikap masyarakat terutama anak-anak muda yang berbohong, kurangnya rasa menghargai dan menghormati kepada yang lebih tua, suka melawan kepada orang tua dan tidak disiplin. Sikap ini merupakan bukti nyata bahwasanya telah terjadi pergeseran nilai-nilai moral individual dilingkungan masyarakat Kecamatan IV Nagari Bayang Utara Kabupaten Pesisir Selatan.

2) Pergeseran Nilai-nilai Moral religius/ketuhanan

Nilai moral religius berkaitan dengan hubungan manusia dengan tuhan berdasarkan keyakinan dan kepercayaannya. Moral religius mencakup tentang percaya kuasa tuha, percaya tuhan itu ada, berserah diri kepada tuhan dan memohon ampun kepada tuhan (Sulistyorini, 2011 : 1). Dalam kehidupan masyarakat di Kecamatan IV Nagari Bayang Utara telah terjadinya pergeseran terhadap nilai moral religius masyarakat yang dahulu dengan sekarang. Dimana masyarakat dahulu rajin beribadah dan mengikuti kegiatan keagamaan, sedangkan sekarang masyarakat lebih cenderung mengabaikan perintah-perintah Allah dan 
melanggar larangan-larangan Allah seperti yang telah diuraikan dalam hasil penelitian ini bahwasanya terlihat perilaku masyarakat yang malas beribadah dan mengikuti kegiatan keagamaan. Hal ini merupakan bukti yang nyata terkait dengan pergeseran nilai moral religius masyarakat di Kecamatan IV Nagari Bayang Utara. Sehingga sekarang banyak permasalahanpermasalahan moral yang terjadi di lingkungan masyarakat. Seperti yang di ungkapkan Daradjat (1973:30) Apabila suatu individu atau kelompok sudah meninggalkan ajaran-ajaran agama maka kaburnya pedomanpedoman moral itu sendiri.

3) Pergeseran Nilai Moral Sosial Nilai moral sosial adalah moral yang menyangkut tentang hubungan manusia dengan manusia lain dalam kehidupan masyarakat atau lingkungan disekitarnya. Moral sosial mencakup bekeja sama, kasih sayang, kerukunan, suka memberi nasehat, peduli nasib orang lain dan suka menolong orang lain (Sulistyorini, 2011: 4-5). Nilai moral sosial mengalami pergeseran dari zaman dahulu dengan sekarang. Dahulu masyarakat peduli dengan keadaan sekitar, saling menghormati dan menghargai baik anak muda terhadap yang lebih tua maupun sebaliknya, namun yang dilihat sekarang kepedulian masyarakat terhadap keadaan dilingkungannya sangat kurang dan hilangnya sikap saling menghormati dan menghargai dilingkungan masyarakat.

2. Faktor Penyebab Terjadinya Pergeseran Nilai-nilai Moral Masyarakat di Kecamatan IV Nagari Bayang Utara

a. Kurang tertanamnya nilai religius masyarakat

Daradjat (1973: mengemukakan semakin jauh masyarakat dari ajaran agama, semakin susah memelihara moral orang dalam masyarakat tersebut dan semakin kacaulah suasana karena semakin banyaknya pelanggaran-pelanggaran atas hak dan hukum.

Kurang tertanamnya nilai religius masyarakat tentunya disebabkan karena kurangnya partisipasi masyarakat dalam kegiatan keagamaan. Masyarakat sekarang cenderung lebih suka berkumpul dan berbincang-bincang di rumah dibandingkan mengikuti kegiatan keagamaan kebanyakan mereka hanya memikirkan kesenangan di dunia dibandingkan di akhir.

b. Kurangnya kontrol sosial masyarakat

Kontrol sosial adalah merupakan suatu mekanisme untuk mencegah penyimpangan sosial serta mengajak dan mengarahkan masyarakat untuk berperilaku dan bersikap sesuai norma dan nilai yang berlaku. Dengan adanya kontrol sosial yang baik diharapkan mampu meluruskan anggota masyarakat yang berperilaku menyimpang / membangkang.

Namun dari hasil penelitian yang peneliti lakukan bahwa kontrol 
sosial masyarakat sangat kurang, dimana masyarakat hanya menasehati tanpa ada melakukan hal seperti sosialisasi atau yang lainnya. Kebanyakan masyarakat lebih memperkuat kontrol terhadap anak-anak mereka agar tidak terbawa pengaruh pergeseran nilai moral yang mengakibatkan timbulnya perilaku amoral.

c. Kurangnya Kontrol Orang tua Pada dasarnya seorang anak cenderung memilih lingkungan yang baik tempat dia bergaul apabila dia mendapatkan bimbingan dari orang tua. Karena tugas dari orang tua adalah mengawasi remaja dalam pergaulannya (Rachman : 2014). Menurut Ulwan (2012) seorang anak yang tidak mendapatkan perhatian, kasih sayang dan bimbingan orang tua layaknya seperti anak yatim yang hidup terasing. Pola pengasuhan dimana orang tua sangat terlibat dalam kehidupan anaknya tetapi tidak ada permintaan atau kontrol dari orang tua di sebut juga dengan indulgent parenting, (Santrock, 2010). Menurut Carr (2009), anak dilepaskan tanpa pengawasan tanpa memerlukan tanggung jawab dari setiap sikap dan tingkah laku perbuatan anakanaknya. Sesuai dengan hasil penelitian ini, bahwasanya kontrol orang tua terhadap anak sangatlah kurang. Seperti halnya orang tua yang jarang mengontrol keseharian anak dalam bersikap pada orang lain, orang tua tidak mengontrol ibadah anak dan ketika anak berada jauh dari mereka anak jadi terbiasa dengan kehidupan yang bebas kontrol dari orang tua. Sehingga pergeseran nilai-nilai moral masyarakat yang diakibatkan oleh kurangnya kontrol orang tua menimbulkan permasalahan seperti hamil diluar nikah.

3. Kasus Hamil Diluar Nikah di Kecamatan IV Nagari Bayang Utara

Menurut Sarwono dalam Lutfiah Nur Aini, Kehamilan diluar nikah merupakan bentuk dari adanya perilaku seksual. Sedangkan menurut agama islam, Hamil diluar nikah merupakan tindakan yang pada dasarnya sangat tidak dianjurkan dalam agama, karena agama mengajarkan manusia pada kebajikan (Aladin. (2017, juli). Pernikahan Hamil Diluar Nikah dalam Perspektif Kompilasi Hukum Islam (KHI) Dan Fiqih Islam Dikantor Urusan Agama. Jilid 46. No.3)

Berdasarkan hasil penelitian, terdapat 8 kasus hamil diluar nikah di Kecamatan IV Nagari Bayang Utara Kabupaten Pesisir Selatan dalam jangka waktu 3 tahun terakhir. Permasalahan ini terjadi karena adanya pergeseran nilai-nilai moral yang terjadi kehidupan masyarakat. Pergeseran nilai moral ini disebabkan karena kurang tertanamnya nilai-nilai religius/agama, kurangnya kontrol sosial masyarakat dan kurangnya kontrol orang tua.

4. Upaya Penanggulangan Pergeseran Nilai-nilai Moral Masyarakat di Kecamatan IV Nagari Bayang Utara 


\section{Upaya Preventif}

Menurut Nurseno (2009 :197)

Pengendalian sosial Preventif merupakan suatu usaha pencegahan terhadap terjadinya gangguan-gangguan pada keserasian antara kepastian dan keadilan. Berdasarkan hasil penelitian diperoleh 2 upaya preventif yang dilakukan pemerintah Nagari Bayang Utara dalam menanggulangi pergeseran nilai-nilai moral masyarakat yaitu diadakannya pelatihan khutbah Jum'at yang bertujuan untuk menanamkan serta meningkatkan nilai-nilai agama agar mereka memiliki nilai religius yang baik terutama anak-anak muda dan dibentuknya Arena Trabas yang bertujuan sebagai wadah untuk anak-anak muda dalam menyalurkan minat dan bakat mereka serta untuk mengurangi perilaku balap-balapan di jalan raya demi kenyamanan dilingkungan masyarakat.

\section{Upaya Represif}

Menurut Nurseno (2009 :197) penanggulangan secara represif nertujuan untuk mengembalikan keserasian yang mengalami gangguan. Usaha represif itu sendiri sperti hukuman atau sanksi terhadap warga masyarakat yang melanggar kaedah yang berlaku dan ajaran agama. Berdasarkan hasil penelitian, diperoleh upaya reprensif yang dilakukan yaitu : 1) Datuak/Niniak mamak mengumpulkan kemanakankemanakan untuk diberikan nasehat dan pengarahan mengenai pergeseran nilai moral yang telah terjadi di Kecamtan IV Nagari Bayang Utara. 2) Upaya represif yang dilakukan orang tua dan masyarakat yaitu memberi nasehat serta meningkatkan kontrol terhadap lingkungan dan keseharian anak agar tidak terjadinya perilaku amoral akibat pergeseran nilainilai moral yang sudah terjadi.

\section{KESIMPULAN}

Berdasarkan temuan dan pembahasan yang telah dilakukan dapat disimpulkan berikut:

1. Pergeseran nilai-nilai moral masyarakat di Kecamatan IV Nagari Bayang Utara Kabupaten Pesisir Selatan dapat dilihat dari 3 aspek yaitu pergeseran nilai-nilai moral individual dilihat dengan banyaknya sikap suka berbohong dan tidak ada sopan santu kepada orang tua maupun orang lain. Lalu pergeseran nilai-nilai moral religius dapat dilihat dengan banyaknya anak-anak muda dan masyarakat yang mengabaikan perintah dan larangan yang ada dalam ajaran agama islam. Sedangkan Pergeseran nilai-nilai moral sosial dilihat dari kurangnya rasa menghormati dan menghargai anak-abak muda kepada orang yang lebih tua serta kepada guru, niniak mamak dan yang lainnya.

2. Pergeseran nilai-nilai moral masyarakat di Kecamatan IV Nagari Bayang Utara disebabkan karena beberapa faktor diantaranya yaitu kurangnya tertanam nilai-nilai religius/keagamaan masyarakat, kurangnya kontrol sosial 
masyarakat dan kurangnya kontrol orang tua.

3. Upaya-upaya yang dilakukan untuk menanggulangi pergeseran nilai-nilai moral masyarakat yaitu melalui upaya preventif dan upaya represif. Upaya preventif yaitu dilakukan oleh pemerintah nagari dengan diadakannya pelatihan khutbah Jum'at dan dibentuknya Arena Trabas. Sedangkan Upaya refresif dilakukan oleh datuak/niniak mamak dengan diberikan nasehat dan pengarahan kepada kemankan-kemanakan mengenai pergeseran nilai moral yang sedang terjadi begitu pun dengan orang tua mereka memberikan nasehat dan lebih meningkatkan kontrol terhadap keseharian anak-anak mereka agar tidak tidak melakukan perilkau amoral yang disebabkan karena terjadinya pergeseran nilai-nilai moral masyarakat.

4. Pergeseran nilai-nilai moral masyarakat menyebabkan anakanak muda melakukan perilakuperilaku amoral, salah satu akibat dari perilaku amoral yaitu hamil diluar nikah yang terjadi pada anak-anak muda di Kecamatan IV Nagari Bayang Utara.

\section{DAFTAR PUSTAKA}

Aladin. (2017). Pernikahan Hamil Diluar Nikah Dalam Perspektif Kompilasi Hukum Islam (KHI) Dan Fiqih Islam Dikantor Urusan Agama (Studi Kasus Di Kota Kupang). Masalah-masalah Hukum. Jilid 46, No. 3

Carr, E.D. (2009). Parenting Style. Emcyclopedia Of The Life Course And Human Development. Vol 1:
Childhood And Adolescence. USA: Macmillan

Daradjat, Daradjat. (1973). Membina Nilai-nilai Moral di Indonesia. Jakarta: Bulan Bintang

Dina Febriani. (2014). "Faktor Penyebab Menurunnya Moral Remaja Dan Upaya Orang Tua Dalam Mengatasinya (Studi Di Nagari Lansek Kadok Kecamatan Rao Selatan Kabupaten Pasaman)" Jurnal STKIP PGRI Sumbar (tidak diterbitkan).

Moleong, Lexi J. (2012). Metodologi Penelitian Kualitatif. Bandung: Rosda Karya

Nurseno. (2009). Sosiologi. Solo: Tiga Serangkai Pustaka Mandiri

Rachman, F.M. (2012). Islamic Teen Parenting. Jakarta: Erlangga

Santrock, J.W. (2010). Psikologi Pendidikan. Edisi Kedua. Terjemahan: Tri wibowo B.S. Jakarta: Kencana Prenada Media Group

Sarwono, Sarlito Wirawan. (2001). Psikologi Remaja. Jakarta: Raja Grafindo Persada. Hlm 141

Sugiyono. (2014). Metode penelitian Kuantitatif Kualitatif dan R\&D. Bandung: Alfabeta

Sulheri Garizing. (2016). “Degradasi Moral Dikalangan Peserta Didik Di SMA Negeri 1 Pinrang". Jurnal Sosisalisasi Pendidikan SosiologiFIS UNM

Sulistyorini. (2011).Memahami Konsep Kinerja Guru

(http://blog.tp.ac.id/Memaham i-Konsep-Kinerja-Guru)

Ulwan, N.A. 2012. Tarbiyatul Aulad Fii Islam (A.R. Hakim Penerj). Solo: Insan Kamil

Willis, Sofyan S. (2008). Remaja \& Masalahnya. Bandung: Alfabeta 